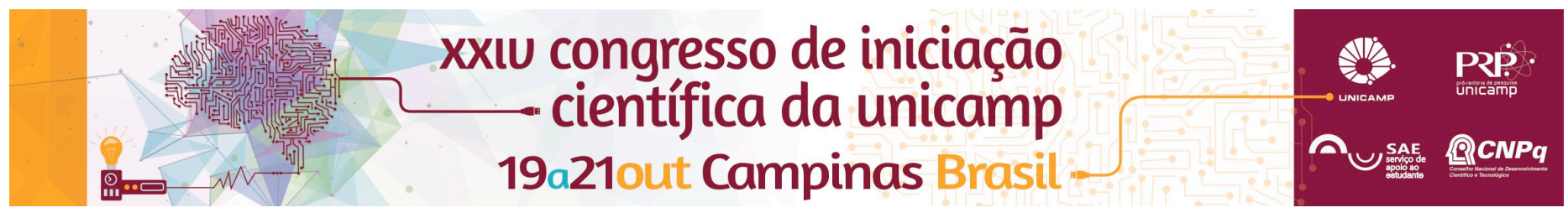

\title{
Análise da estrutura global de propriedade e de geração de conhecimento do setor de software e serviços no período recente
}

\author{
Natália Vial C e Silva* e Ivette Luna
}

\section{Resumo}

Este trabalho tem como objetivo principal a análise de estruturas de propriedade das grandes corporações na economia global relacionadas à indústria de software e serviços, considerando diferentes aspectos como, por exemplo, internacionalização de mercados e estratégias, a identificação dos agentes concentradores de poder de comando no que se refere à capacidade de geração de valor agregado, assim como do poder de decisão com relação ao progresso técnico e a produção industrial.

\section{Palavras-chave:}

Indústria, Software, Inovação.

\section{Introdução}

O projeto visa a análise das estruturas de propriedade e o desenvolvimento tecnológico do setor de software a partir das grandes corporações do segmento $e$ as suas subsidiárias diretas. A partir da identificação destas estruturas e do perfil inovador das mesmas, espera-se que seja possível também estabelecer relações entre as mudanças estruturais e o desempenho das principais empresas globais.

\section{Resultados e Discussão}

A partir da análise das empresas com maiores gastos em P\&D do setor, optou-se pela análise de cinco empresas significativas nesse setor, sendo elas, a Google, a Microsoft, a IBM, a SAP e a Fujitsu, escolhidas através de sua representatividade no setor segundo $O$ R\&D Scoreboard ${ }^{1}$, como resume a Tabela 1.

Tabela 1 - Visão Geral dos Resultados

\begin{tabular}{|c|c|c|c|c|c|c|c|}
\hline Ranking & Empresa & Pais & $\begin{array}{l}\text { P\&D } 2014 \\
\text { (Emihöes) }\end{array}$ & $\begin{array}{c}\text { Vendas 2014 } \\
\text { (Emilhöes) }\end{array}$ & P\&D/vendas & $\begin{array}{c}\text { Market } \\
\text { Share no } \\
\text { setor }\end{array}$ & $\begin{array}{c}\text { Funcionários } \\
2014\end{array}$ \\
\hline 3 & MICROSOFT & EUA & $9.921,7$ & \begin{tabular}{|l|}
$77.077,6$ \\
\end{tabular} & \begin{tabular}{|c|}
0,13 \\
\end{tabular} & 0,12 & 118.000 \\
\hline 6 & GOOGLE & EUA & $8.098,2$ & $54.362,1$ & 0,15 & 0,09 & 53.600 \\
\hline 25 & IBM & EUA & $4.335,7$ & $76.429,4$ & 0,06 & 0,12 & 379.592 \\
\hline 50 & SAP & ALE & $2.307,0$ & $17.560,0$ & 0,13 & 0,03 & 74.406 \\
\hline 84 & \begin{tabular}{|l|} 
FUJITSU \\
\end{tabular} & JAP & $1.384,1$ & $32.452,0$ & 0,04 & 0,05 & 158.846 \\
\hline
\end{tabular}

Além dos gastos em P\&D, essas empresas possuem outras estratégias corporativas muito importantes como as fusões e aquisições (M\&A) e as carteiras de patentes, como mostra a Tabela 2. As operações de $M \& A$ apresentam alguns padrões que levam em conta a sobreposição da base de conhecimento das empresas envolvidas e da relevância da carteira de patentes para a realização das transações. Assim, visando a garantia dos lucros resultantes das atividades inovativas, as patentes podem ser entendidas enquanto mecanismos de apropriação do conhecimento embutido na aplicação (solicitação da patente), tornando-se assim um mecanismo de proteção e/ou barreira a entrada muito utilizado entre as empresas de alta tecnologia.

Tabela 2 - Ranking de Patentes ${ }^{2}$ e Aquisições Realizadas

\begin{tabular}{|r|l|r|r|r|}
\hline Ranking em 2015 & Empresa & Concessōes em 2015 & Concessōes em 2014 & Aquisiçōes (2000- 2016) \\
\hline 1 & IBM & 7,355 & 7,534 & 154 \\
\hline 5 & Google & 2,835 & 2,566 & 192 \\
\hline 10 & Microsoft & 1,956 & 1 & 150 \\
\hline 19 & Fujitsu & 1,467 & 1,82 & 4 \\
\hline 65 & SAP SE & 571 & 609 & 53 \\
\hline
\end{tabular}

E, a fim de assegurar a geração e o acúmulo de conhecimento, além da qualificação técnica da mão de obra, as indústrias do setor mantém estratégias de inovação próprias, sendo a maioria delas em forma de programas e laboratórios de pesquisa como mostra a Tabela abaixo.

Tabela 3 - Programas de Pesquisa

\begin{tabular}{|l|l|l|r|}
\multicolumn{1}{|c|}{ Empresa } & \multicolumn{1}{|c|}{ País } & Programa de Pesquisa & Número de Laboratórios \\
\hline MICROSOFT & EUA & Microsoft Research & 7 \\
\hline GOOGLE & EUA & Google Brain Team and Google NLU Team & 0 \\
\hline IBM & EUA & IBM Research & 12 \\
\hline SAP & ALE & SAP Research & 12 \\
\hline FUJITSU & JAP & Fujitsu Laboratories & 9 \\
\hline
\end{tabular}

\section{Conclusões}

De acordo com Britto e Stallivieri $(2010)^{3}$ o dinamismo e o impacto difuso das inovações geradas pela indústria de software refletem-se em elevadas taxas de nascimento e mortalidade de firmas, bem como numa tendência à volatilidade de lucros e market-shares.

O conhecimento é um fator competitivo crítico no setor, constituindo o principal gerador de vantagens competitivas e de posições monopolistas no setor. E mesmo que os segmentos mais rentáveis e padronizados sejam dominados por grandes empresas multinacionais, o setor também apresenta grandes oportunidades para MPEs, principalmente na atuação local/regional.

Em resumo, dado o crescente processo internacionalização de mercados e estratégias, a qualidade e produtividade converteram-se em fatores determinantes da competitividade empresarial. Cabe salientar também que o desenvolvimento de software não é necessariamente uma atividade apenas intensiva em P\&D. Assim a partir da análise realizada, observa-se que aspectos envolvendo mais diretamente a acumulação de conhecimentos, a qualificação técnica do pessoal, a realização de esforços metodológicos e o aprofundamento da interação com clientes mais sofisticados são outras importantes características para enfrentar os concorrentes neste mercado.

\footnotetext{
1 The EU Industrial R\&D Investment Scoreboard

${ }^{2}$ http://www.ificlaims.com/index.php?page=rankings_top_US_assignees. Acesso em 4 de julho de 2016.

${ }^{3}$ Britto, Jorge; Stallivieri, Fabio (2010) Inovação, cooperação e aprendizado no setor de software no Brasil: análise exploratória baseada no conceito de Arranjos Produtivos Locais (APLs). Economia e Sociedade, Campinas, vol. 19, n. 2, p 315-358.
} 